\title{
Attenuation of stress-induced anorexia in brown trout (Salmo trutta) by pre-treatment with dietary L-tryptophan
}

\author{
Erik Höglund $^{1 *}$, Christina Sørensen ${ }^{2}$, Marit Jørgensen Bakke ${ }^{3}$, Göran E. Nilsson ${ }^{2}$ and $\emptyset y v i n d ~ Ø v e r l i{ }^{4}$ \\ ${ }^{1}$ Danish Institute for Fisheries Research, Department of Marine Ecology and Aquaculture, North Sea Center, Postbox 101, DK- \\ 9850 Hirtshals, Denmark; and Aquaculture Protein Centre, Center of Excellence, PO Box 5503, As N-1432, Norway \\ ${ }^{2}$ Physiology Programme, Department of Molecular Biosciences, University of Oslo, PO Box 1041, N-0316 Oslo, Norway \\ ${ }^{3}$ Department of Food Safety and Infection Biology, Norwegian School of Veterinary Science, PO Box 8148, N-0033 Oslo, Norway \\ ${ }^{4}$ Department of Animal and Aquacultural Sciences, Norwegian University of Life Sciences, PO Box 5003, As, Norway
}

(Received 3 July 2006 - Revised 6 November 2006 - Accepted 14 November 2006)

\begin{abstract}
The general consensus is that brain serotonin (5-HT) inhibits feed intake in teleost fishes and other vertebrates. Dietary manipulations with the 5HT precursor tryptophan (TRP) have, however, yielded contradictory effects on feed intake, while studies of the endocrine response to stress indicate that the effects of TRP-enriched feed are context dependent. A characteristic behavioural response to stress is a reduction in feed intake, and in the present study we investigated whether pre-treatment with TRP-enriched feed affected stress-induced changes in feeding behaviour in brown trout (Salmo trutta). After acclimatisation in observation aquaria, isolated fish were fed control or TRP-supplemented feed for $7 \mathrm{~d}$, whereupon they were transferred to a novel environment, in which all fish were fed control feed. Transfer to a new environment resulted in decreased feeding in both the TRP pre-treated and the control-treated group. However, this decrease was more pronounced in the control-treated group. Previous experiments have concluded that stimulation of brain 5-HT systems by TRP enhancement does not affect feed intake in salmonid fishes, but in these studies food intake was observed in unstressed animals only. The present study suggests that pre-treatment with dietary TRP attenuates stressinduced anorexia. Hence, it appears that the effect of dietary manipulations of TRP on feeding behaviour is dependent on the stress levels experienced by experimental animals. These behavioural data are discussed in the context of the involvement of 5-HT in appetite regulation.
\end{abstract}

Feeding: Stress: Tryptophan: Teleost: Behaviour

In mammals, the synthesis of serotonin (5-HT) in the brain is dependent upon availability of its precursor, the amino acid tryptophan (TRP) (Leathwood, 1987; Fernstrom \& Wurtman, 1997). This occurs because the rate-limiting enzyme in the biosynthetic pathway of 5-HT, tryptophan hydroxylase, is unsaturated with TRP under normal physiological conditions. Further, TRP enters the brain from the circulation through a protein transporting not only TRP but also other large neutral amino acids (LNAA) (Fernstrom \& Wurtman, 1997). Dietary manipulations affecting plasma TRP/LNAA ratios have been used as a tool to investigate involvement of the 5-HT system in behaviour, mood and cognition in humans (Markus et al. 1999, 2000). Such manipulations have also been shown to affect the endocrine and behavioural response to stress in comparative vertebrate models (Winberg et al. 2001; Lepage et al. 2002, 2003; Höglund et al. 2005).

A characteristic behavioural response to stress in all vertebrates appears to be a reduction in food intake (Carr, 2002). Stress-induced anorexia could in part be an effect of central 5-HTergic activation, since a general consensus is that increased 5-HT neurotransmission inhibits food intake (e.g. Leibowitz \& Alexander, 1998). However, information on the appetite-regulating role of 5-HT in vertebrates other than mammals is meagre. In teleosts, chronic stress, which induces increased brain turnover of 5-HT, is associated with suppressed appetite (Øverli et al. 1998; Ortega et al. 2005). Further, a central anorectic action of 5-HT was demonstrated by intracerebroventricular injection of 5-HT in goldfish (De Pedro et al. 1998) and also by intraperitoneal injections of the serotonin-releasing agent fenfluramin in rainbow trout (Ruibal et al. 2002). TRP treatment, on the other hand, has been shown to act in both a stimulatory and an inhibitory way, and to have no effect on appetite in domestic hens (Rosebrough, 1996), pigs (Seve, 1999) and rats (Haleem et al. 1998).

Studies in rainbow trout show that enhancement of 5-HT signalling by TRP-enriched feed has context-dependent effects on the endocrine stress response. In undisturbed individuals, a $7 \mathrm{~d}$ treatment with TRP-enriched feed induced a slight increase in cortisol release, while individuals exposed to an acute stressor showed decreased cortisol release (Lepage et al. 2002, 2003). Long-term enhancement of central 5-HT signalling by selective serotonin re-uptake inhibitors also inhibits the endocrine stress response in both teleost fish and mammals

\footnotetext{
Abbreviations: 5-HT, serotonin; LNAA, large neutral amino acids; TRP, tryptophan. * Corresponding author: Dr Erik Höglund, fax +47-64965101, email erh@difres.dk
} 
(Jensen et al. 1999; Lepage et al. 2005). However, long-term effects of enhanced 5-HT signalling on behavioural responses such as feeding have, to our knowledge, not been investigated in teleosts. The aim of the present study was to investigate if stress-induced changes in feeding behaviour were affected by $7 \mathrm{~d}$ of pre-treatment with TRP-enriched feed in brown trout.

\section{Material and methods}

\section{Animals}

The experimental fish were 1-year-old brown trout (Salmo trutta) (body mass, 19.6 g (SD 2.6), $n$ 16). Before the start of the experiment, fish were kept indoors in a holding tank $\left(200 \mathrm{fish} / \mathrm{m}^{2}\right)$, continuously supplied with aerated water at $8-10^{\circ} \mathrm{C}$, for $>2$ months. The fish were hand-fed with commercial trout pellets (Ewos ST40) at $1-2 \%$ of the body mass per day. The light/dark regime was $12 / 12 \mathrm{~h}$.

\section{Experimental fish feed}

Wet feed was prepared following Winberg et al. (2001). In brief, $1 \mathrm{~kg}$ of herring (Clupea harengus) fillets and $1 \mathrm{~kg}$ of shrimp (Pandalus borealis) were minced together and divided into two $1 \mathrm{~kg}$ portions. Hot water $(0.5 \mathrm{l})$ with gelatine $(50 \mathrm{~g})$ was added to each portion. One feed batch was supplemented with $3 \mathrm{~g}$ of TRP, resulting in a TRP/LNAA ratio of $0 \cdot 22$. The unsupplemented feed batch with a [TRP]/[LNAA] ratio of 0.06 served as control feed. Thin sheets $(3 \mathrm{~mm}$ thick) of the feed mixes were frozen and kept at $-20^{\circ} \mathrm{C}$. Before use, frozen feed was divided in $3 \times 3 \times 3 \mathrm{~mm}$ cubes with a scalpel. Amino acid analysis of the two experimental feeds was carried out according to approved EU methods (OJ, 1998, 2000) on a Biochrom 30 Amino Acid Analyser (Biochrom Ltd, Cambridge, UK) for the LNAA, except TRP which was analysed in a Dionex Summit HPLC system, with the addition of a Shimadzu RF-535 fluorescence detector.

\section{Experimental protocol}

The experiment was divided into three phases; acclimation; TRP pre-treatment; and a stress phase. In all these phases, 16 fish were kept individually isolated. Feeding behaviour was quantified daily by the feeding score described by $\emptyset$ verli et al. (2006). In brief, from the first day after transfer to social isolation, fish were hand-fed, and feeding behaviour was rated according to the following scale:

Score 0: the fish did not show any interest in the presented feed, and was immobile in a corner of the aquarium.

Score 1: the fish showed some interest in the presented feed, but did not move or moved little and slowly to catch feed, and consumed $0-5 \%$ of the offered feed.

Score 2: the fish showed interest in the presented feed and left the location where they were placed before feeding to catch feed, but always returned to this place between consuming feed pieces. Fish given this score consumed $5-50 \%$ of the offered feed.

Score 3: The fish showed a high degree of interest in the presented feed, searched for feed actively and did not return to the spot where they were located before feeding. Fish given this score consumed $50-100 \%$ of the offered feed.

On this scale, $100 \%$ of the offered experimental wet feed equals a feeding ratio at $10 \%$ of the body mass per day (corresponding to approximately $1 \%$ dry feed $/ \mathrm{kg}$; Winberg et al. 2001). The acclimation and the TRP pre-treatment phases were conducted in four $100 \mathrm{~cm} \times 50 \mathrm{~cm} \times 50 \mathrm{~cm}$ glass aquaria, continuously supplied with aerated water $\left(11 / \mathrm{min}, 10-12^{\circ} \mathrm{C}\right)$. These aquaria were divided into four chambers by grey plastic walls, where the fish were kept individually isolated. The stress phase was conducted in plastic $25 \mathrm{~cm} \times 20 \mathrm{~cm} \times 20 \mathrm{~cm}$ aquaria, continuously supplied with aerated water $(11 / \mathrm{min}$, $\left.10-12^{\circ} \mathrm{C}\right)$.

The acclimatisation phase lasted from day 1, after transfer from the holding tank to the observations aquaria, to day 28 . At the end of this period, the mean feed response index reached 1.8 (Fig. 1), and all fish were reactive to the presented feed.

In the TRP pre-treatment phase, eight fish were given TRPsupplemented experimental feed for $7 \mathrm{~d}$ (day 29-35), whereas the remaining eight fish were given control feed throughout the experiment. One individual in the TRP treated group was excluded from the data analyses, since it did not consume any feed during the last $2 \mathrm{~d}$ of the TRP pre-treatment phase.

On the morning before feeding at the start of the stress phase (day 36), fish were netted and lifted up from the glass aquaria and inserted individually into much smaller plastic aquaria. After transfer, both the TRP-pre-treated group and the control group received control feed, and the feeding behaviour was quantified on the day of transfer and for a further $3 \mathrm{~d}$ (day 37-39).

\section{Statistical analyses}

All data are presented as mean and standard error of the mean (SEM) unless stated otherwise. When analysing the effects of TRP pre-treatment on stress-induced change in feeding behaviour, the total feeding score observed during $4 \mathrm{~d}$ following transfer was analysed with the Mann-Whitney $U$ test. Statistical analyses were performed using Statistica 5.1 (StatSoft Inc.).

\section{Results and Discussion}

The stress of being transferred and put into smaller aquaria resulted in a decrease in feeding score in both TRP pre-treated

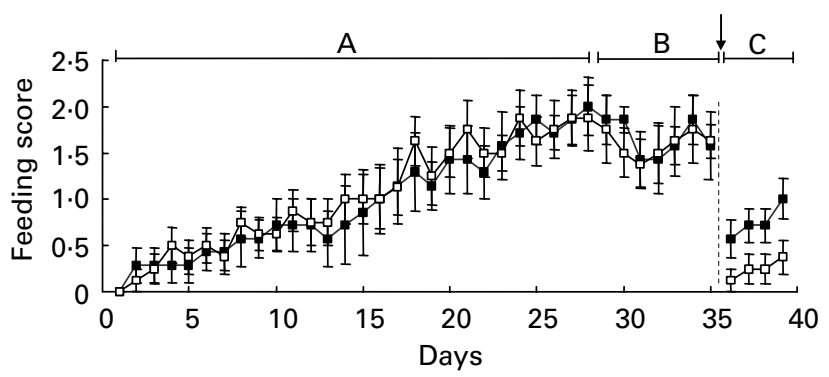

Fig. 1. Mean feeding score during the acclimatization (A), L-typtophan (TRP) pre-treatment $(B)$ and stress phase $(C)$ in juvenile brown trout. One group ( $n$ 7) was fed wet feed supplemented with $3 \mathrm{~g} / \mathrm{kg}$ TRP $7 \mathrm{~d}$ before transfer and unsupplemented control feed during the acclimatization and stress phase, while the control-treated group $(n 8)$ was fed unsupplemented feed throughout the experiment. An arrow indicates transferring the fish to a new environment. Values are means and SEM. (ם) TRP; ( $\square$ ) control. 
and control-treated groups. However, a significantly higher total feeding score in the TRP-pre-treated group compared with the control-treated group was observed during the $4 \mathrm{~d}$ following transfer $(0.8$ (SD 0.16) v. 0.4 (SD 0.13); $P<0.05$, $Z=1 \cdot 97$, Mann-Whitney $U$ test), suggesting that TRP attenuates stress-induced anorexia.

Previous studies of the effect of TRP treatment on feeding behaviour and/or growth rate in vertebrates show contradictory results (Rosebrough, 1996; Haleem et al. 1998; Seve, 1999; Hussein et al. 2001; Winberg et al. 2001; Hseu et al. 2003; Tormo et al. 2004; van Hierden et al. 2004; Papoutsoglou et al. 2005).

The present study demonstrates an improved feeding after a stressful event in TRP-pre-treated fish compared with control-treated fish. This suggests context-dependent effects of TRP on feeding behaviour. Furthermore, this observation implies that differences in uncontrolled stress during experimentation could be the reason for some of the variation between previous studies on the effect of TRP on feeding behaviour.

The inclusion rate of TRP used in the present study has been shown to enhance 5-HT signalling in juvenile grouper (Epinephelus coioides) and in rainbow trout (Winberg et al. 2001; Lepage et al. 2002, 2003; Huseu et al. 2003). This observation is in accordance with the general consensus that increased availability of TRP to the brain enhances central 5-HTergic synthesis in vertebrates (Fernstrom \& Wurtman, 1997; Aldegunde et al. 2000; Winberg et al. 2001; Höglund et al. 2005).

5-HT is generally considered to have an anorectic effect (e.g. Leibowitz \& Alexander, 1998) and to act in a stimulatory manner on the endocrine stress response (Chauloff, 1993). A positive relationship between chronic stress, increased brain turnover of 5-HT and suppressed appetite has also been demonstrated in teleosts (Øverli et al. 1998; Ortega et al. 2005). Further, an anorectic action of 5-HT has been demonstrated by central administration in goldfish (De Pedro et al. 1998) and oral administration in European sea bass (Rubio et al. 2006). However, the present study and previous studies in rainbow trout show that TRP treatment does not affect feeding behaviour in undisturbed fish. Moreover, studies in rainbow trout demonstrate a suppressive effect on the endocrine stress response by TRP-enriched feed (Lepage et al. 2002, 2003). Furthermore, this and other effects, such as decreased aggression (Winberg et al. 2001), which is associated with changes in the 5-HTergic system, were first evident after $7 \mathrm{~d}$ of TRP treatment. This suggests that the behavioural and endocrine effects of TRP-enriched feed are mediated by an indirect mechanism related to increased 5-HTergic activity and release. The effects of TRP and $7 \mathrm{~d}$ of treatment with the serotonin reuptake inhibitor citalopram on aggression and the endocrine stress response are remarkably similar (Lepage et al. 2005). Since both serotonin reuptake inhibitors and TRP are expected to increase 5-HTergic synaptic transmission acutely, Lepage et al. (2005) suggested common long-term mechanisms, such as changes in 5-HTergic receptor expression or sensitivity, for these two treatments. Moreover, brain 5-HT is under the control of and controls the release of hypothalamic neuropeptides, playing important roles in mediating stress-induced inhibition of feeding (Bernier, 2006). Among these are the melanocortins and corticotrophin-releas- ing hormone-like peptides (Carr, 2002; Bernier, 2006). Further studies are needed to investigate if TRP enrichment affects these neuropeptides, and changes in 5-HTergic receptor expression and sensitivity.

In conclusion, the present study demonstrates that pre-treatment with dietary TRP attenuates stress-induced anorexia in brown trout. Further, the present result also shows that the behavioural effect of TRP is context dependent, which could explain some of the variation in results between previous studies on the effect of TRP on feeding behaviour.

\section{References}

Aldegunde M, Soengas JL \& Rozas G (2000) Acute effects of L-tryptophan on tryptophan hydroxylation rate in brain regions (hypothalamus and medulla) of rainbow trout (Oncorhynchus mykiss). J Exp Zool 286, 131-135.

Bernier NJ (2006) The corticotropin-releasing factor system as a mediator of the appetite-suppressing effects of stress in fish. Gen Comp Endocrinol 146, 45-55.

Carr JA (2002) Stress, neuropeptides, and feeding behavior: a comparative perspective. Integr Comp Biol 42, 582-590.

Chauloff F (1993) Physiopharmacological interactions between stress hormones and central serotonergic systems. Brain Res Rev 18, $1-32$.

De Pedro N, Pinillos ML, Valenciano AI, Alonso-Bedate M \& Delgado MJ (1998) Inhibitory effect of serotonin on feeding behavior in goldfish: involvement of CRF. Peptides 19, 505-511.

Fernstrom JD \& Wurtman RJ (1997) Brain serotonin content: physiological regulation by plasma neutral amino acids (Reprinted). Obes Res 5, 377-380.

Haleem DJ, Jabeen B \& Parveen T (1998) Inhibition of restraintinduced anorexia by injected tryptophan. Life Sciences $\mathbf{6 3}$, $\mathrm{P} 1205-\mathrm{P} 1212$.

Höglund E, Bakke MJ, Øverli Ø, Winberg S \& Nilsson GE (2005) Suppression of aggressive behaviour in juvenile Atlantic cod (Gadus morhua), by L-tryptophan supplementation. Aquaculture 249, 525-531.

Huseu JR, Lu FI, Su HM, Wang LS, Tsai CL \& Hwang PP (2003) Effect of exogenous tryptophan on cannibalism, survival and growth in juvenile grouper, Epinephelus coioides. Aquaculture 218, 251-263.

Hussein AS, Cantor AH, Pescatore AJ, Gates RS, Burnham D, Ford MJ \& Paton ND (2001) Effect of low protein diets with amino acid supplementation on broiler growth. J Appl Poultry Res 10, 354-362.

Jensen JB, Jessop DS, Harbuz MS, Mork A, Sanchez C \& Mikkelsen JD (1999) Acute and long-term treatments with the selective serotonin reuptake inhibitor citalopram modulate the HPA axis activity at different levels in male rats. $J$ Neuroendocrinol 11, 465-471.

Leathwood PD (1987) Tryptophan availability and serotonin synthesis. Proc Nutr Soc 46, 143-156.

Leibowitz SF \& Alexander JT (1998) Hypothalamic serotonin in control of eating behavior, meal size, and body weight. Biol Psychiatry 44, 851-864.

Lepage O, Larson ET, Mayer I \& Winberg S (2005) Serotonin, but not melatonin, plays a role in shaping dominant-subordinate relationships and aggression in rainbow trout. Horm Behav 48, $233-242$.

Lepage O, Tottmar O \& Winberg S (2002) Elevated dietary intake of L-tryptophan counteracts the stress-induced elevation of plasma cortisol in rainbow trout (Oncorhynchus mykiss). J Exp Biol 205, 3679-3687.

Lepage O, Vilchez IM, Pottinger TG \& Winberg S (2003) Timecourse of the effect of dietary L-tryptophan on plasma cortisol 
levels in rainbow trout Oncorhynchus mykiss. J Exp Biol 206, 3589-3599.

Markus CR, Panhuysen G, Jonkman LM \& Bachman M (1999) Carbohydrate intake improves cognitive performance of stress-prone individuals under controllable laboratory stress. $\mathrm{Br} \mathrm{J}$ Nutr 82, 457-467.

Markus R, Panhuysen G, Tuiten A \& Koppeschaar H (2000) Effects of food on cortisol and mood in vulnerable subjects under controllable and uncontrollable stress. Physiol Behav 70, 333-342.

OJ (1998) Commission Directive 98/64/EC establishing community methods of analysis for the determination of amino acids, crude oils and fats, and olaquindox in feedingstuffs and amending directive 71/393/EEC. Official J Eur Comm L 257, 14-28.

OJ (2000) Commission Directive 2000/45/EC establishing community methods of analysis for the determination of vitamin A, vitamin $\mathrm{E}$ and tryptophan in feedingstuffs. Official J Eur Comm L 174, 32-50.

Ortega VA, Renner KJ \& Bernier NJ (2005) Appetite-suppressing effects of ammonia exposure in rainbow trout associated with regional and temporal activation of brain monoaminergic and CRF systems. J Exp Biol 208, 1855-1866.

$\emptyset$ verli $\varnothing$, Sørensen S \& Nilsson GE (2006) Behavioral indicators of stress-coping style in rainbow trout: do males and females react differently to novelty? Physiol Behav 87, 506-512.

Øverli Ø, Winberg S, Damsgård B \& Jobling M (1998) Food intake and spontaneous swimming activity in Arctic char (Salvelinus alpinus): role of brain serotonergic activity and social interactions. Can J Zool 76, 1366-1370.
Papoutsoglou SE, Karakatsouli N \& Chiras GL (2005) Dietary L-tryptophan and tank colour effects on growth performance of rainbow trout (Oncorhynchus mykiss) juveniles reared in a recirculating water system. Aquacult Eng 32, 277-284.

Rosebrough RW (1996) Crude protein and supplemental dietary tryptophan effects on growth and tissue neurotransmitter levels in the broiler chicken. Br J Nutr 76, 87-96.

Ruibal C, Soengas JL \& Aldegunde M (2002) Brain serotonin and the control of food intake in rainbow trout (Oncorhynchus mykiss): effects of changes in plasma glucose levels. J Physiol 188, 479-484.

Rubio VC, Sanchez-Vazquez FJ \& Madrid JA (2006) Oral serotonin administration affects the quantity and the quality of macronutrients selection in European sea bass Dicentrarchus labrax L. Physiol Behav 87, 7-15.

Seve B (1999) Physiological roles of tryptophan in pig nutrition. Adv Exp Med Biol, 467, 729-741.

Tormo MA, de Tejada AR, Morales I, Paredes S, Sanchez S, Barriga C \& Hernandez R (2004) Orally administered tryptophan and experimental type 2 diabetes. Mol Cell Biochem 261, 57-61.

van Hierden YM, Koolhaas JM \& Korte SM (2004) Chronic increase of dietary L-tryptophan decreases gentle feather pecking behaviour. Appl Anim Behav Sci 89, 71-84.

Winberg S, Øverli Ø \& Lepage O (2001) Suppression of aggression in rainbow trout (Oncorhynchus mykiss) by dietary L-tryptophan. J Exp Biol 204, 3867-3876. 